\section{Regreso al}

mediterráneo

en la

\section{cinematografía de Bigas Luna}

\section{Carolina Sanabria *}

\section{RESUMEN}

El artículo pretende un acercamiento a dos de los filmes de Bigas Luna, Bambola y Son de mar, producidos luego de que la trilogía ibérica (Jamón jamón, Huevos de oro y La teta y la luna) lo catapultara a nivel internacional. Parece que el director catalán quiso combinar historias de componente erótico ambientadas en el mismo entorno del Mediterráneo.

\section{PALABRAS CLAVE}

Bigas Luna - erotismo - muerte - sexualidad-adaptación - Bambola - Son de mar

* Doctora en Comunicación Audiovisual y Publicidad por la Universitat Autónoma de Barcelona. Profesora de la Escuela de Estudios Generales de la Universidad de Costa Rica.

Rec. 27/11/08 Acep. 16/9/09

\section{ABSTRACT}

This article approaches two films by Bigas Luna, Bambola and Son de mar (Sound of the Sea), produced after the Iberian trilogy -Jamón jamón, Huevos de oro (Golden Balls) y La teta y la luna (The Tit and The Moon)-catapulted him to worldwide fame. It seems that the Catalan director wanted to combine erotic stories set in the same Mediterranean environment.

\section{KEYWORDS}

Bigas Luna, erotism, death, sexuality, adaptation, Bambola and Son de Mar (Sound of the Sea)

\section{INTRODUCCIÓN}

A pesar de la irrecusable distancia -en contenido y en espacio temporal- que los separa, dos de los filmes más eróticos del director catalán Bigas Luna, Bambola y Son de mar, parecen estar unificados por una voluntad de recuperación del espíritu de la trilogía ibérica -en tanto comparten no sólo la obsesividad de sus personajes (desde distintas maneras) por la mujer, sino la sensualidad y la ambientación mediterráneas-.

\section{La bella y la bestia}

Además de una irregular aceptación por la crítica, Bambola (1996), una película de "sexo y pasiones", 


\section{ESPIGA}

vino precedida por un conflicto personal que trascendería a la prensa. La controversia en cuestión podría configurar una nueva modalidad de censura -una suerte de censura estética: unos planos que la actriz deseaba eliminar por considerar lesivos a su honorabilidad (según ella) o a su cosmética (según Bigas) ${ }^{1}$.

A diferencia de la trilogía roja, el componente sexual y la violencia de Bambola aparecen tratados de modo más frontal. Como suele ocurrir en la producción del autor, la película, ambientada en la costa italiana, es una sucesión de tragedias a raíz de un solo desencadenante: Mina ("Bambola") -una especie de actualización de Lola- (Fig 1).

Su belleza está ligada a la fatalidad, que empieza por la muerte de Ugo -el socio de la pizzería- hasta la aparición de Furio -más bien caricatura (antes que personaje) de la intemperancia-. Según se desprende de las primeras sílabas de su nombre, el peligroso exconvicto hace alusión a las primeras dos

1. "Valeria ha dicho que no quería que salieran algunas escenas por cuestiones de sexo, lo que no es verdad; es por razones estéticas más que éticas", declaró el director (en Martí Font, 22.10.1996: 37). sílabas del adjetivo relativo a la furia. A nivel sociológico, interviene en su diferenciación el uso de un ideolecto distinto. No casualmente -en el arte nada lo es- está interpretado por Jorge Perugorría, un actor con marcado acento cubano (latinoamericano).

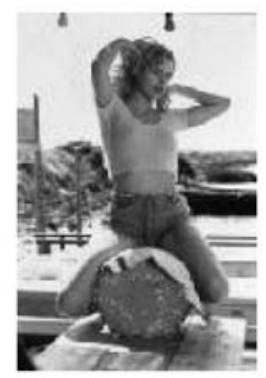

Fig 1: Bambola posando

Tanto "Bambola" como Furio reproducen el paradigma fundacional, en el arte cinematográfico, de la bella y la bestia, la celebérrima cinta de Cooper y Schoedsack, King Kong (1933). El reproche que ella le hace a Furio por su ausencia de alma rememora de alguna manera las disputas recogidas en las múltiples crónicas y relaciones de la conquista de América, polarizadas en dos posiciones $^{2}$, una de

2. Grosso modo, las dos visiones del indígena que privaban durante la conquista y colonización de América se formalizaban en la posición representada por fray Bartolomé de las Casas y su teoría 
las cuales asociaba a los nativos con la barbarie y les negaba la posibilidad de esencia espiritual. "¿Sabes dónde está mi alma?", le increpa en uno de sus arrebatos para, cogiéndose sus genitales, responder de inmediato: “¡Aquí está mi alma!". Su desaforada conducta es un indicador de barbarie, según constantes evaluaciones de ella -un salvaje, una bestia, un animal-. Habría aquí un nuevo desplazamiento de la atribución de barbarie: de la hispanidad -de Mario, en Lola (1985) del mismo director- a la americanidad -de Furio-. Síntoma de una hipervirilidad que en la insistente reafirmación termina cuestionándose a sí misma, Furio no concede distinción de sexualidades -Arsenio, uno de los peligrosos presos que lo obedecen, se dirige a él como "amor", y ya fuera de la cárcel, provoca a Flavio, el hermano homosexual de "Bambola", mostrándosele desnudo al salir de la ducha-. Parte de su salvajismo es, como el patriarca otoñal y

de que los naturales tenían alma, por lo que eran susceptibles de ser evangelizados. Esta visión contrastaba con la de fray Luis de Sepúlveda, que al asociarlos al canibalismo, proponía su carencia de alma y la cristianización mediante el uso de la fuerza -en realidad, diferían en el método de sujeción a la fe, no en el contenido-. decadente de la novela de García Márquez, su costumbre de dormir en el suelo, en contraste incluso con la mascota -esta vez una cabrita $^{3}-$, que lo hace en la cama junto a su dueña. Como el caniche Dani, la cabra es un ser observador del descarnado mundo de los hombres. Bigas plantea de nuevo una humanización del animal -al que una vez más se le asignan nombres personales (Amalia, Lilli)- hasta el punto de que en los créditos finales de reparto el nombre de la segunda cabra incluye apellido (¡Beruony!). En dos ocasiones los hermanos la salvan de la muerte -de la sartén-, lo que no ocurre con el asesinato necesario de la bestia enamorada (como ironizan los créditos finales), no sólo porque los animales se representan con mayor capacidad de conviven-

3. La opinión popular relaciona el trastorno momentáneo de determinación arbitraria o de antojo a estos animales extremado hasta la locura ("estar más loco que una cabra"), pero, en contraste con los personajes -sobre todo Furio-, la cabra es el más cuerdo de todos, como explica Bigas: "Los Caprichos de Goya fueron calificados así porque correspondían a alguien que, como una cabra, iba en todas direcciones y hacía cosas imprevisibles. Capra-capricho. En Bambola es la capra, la pobre Lili [sic], la que observa atónita las locuras de Furio. Lili [sic] es la más cuerda de toda la historia" (en Sánchez, 1999: 125). 


\section{ESPIGA}

cia pacífica -ya que están dotados de unos mecanismos reguladores que hacen que en los combates casi nunca lleguen a la muerte del vencido (Girard, 1983: 152), como sí sucede con los personajes-, sino porque son asumidos como el objeto sobre el cual volcar el afecto ante la desolación que aquellos producen: el abatimiento de "Bambola" ante la muerte de Amalia no tiene parangón con el de su madre. En términos de Seguin, hay una humanización en algunos animales, una aspiración que encuentra su contrapartida -o su compensación- en la figura humana que se degrada y se descompone (en VV. AA., 2001: 21).

Desde Bernardo, la animalidad continúa siendo atributiva del hombre: aparte de sus desbordados impulsos, Furio se conduce por el olor. En efecto: lo primero que hace al tener de cerca a "Bambola" es olerla a ella y luego a sus bragas. Además de dormir en el suelo, sus costumbres denotan una ausencia de civilidad: come con las manos, no suele usar calzado y tampoco se conmueve cuando, tras encerrar a "Bambola", la escucha llorar desconsoladamente. Es más: su reacción inmediata es levantarse a comer. Aunado a ello, los indicios de su propio discurso denotan una interiorización de su propia imagen bestial: "Me han soltado por buena conducta", dice, enunciado que evidencia una autopercepción de sí mismo como una bestia salvaje que ha debido ser confinada. Al inscribirse en esta tradición de la violencia, lecturas externas (y extremas) como las de Kinder -en su texto de elocuente título, Blood Cinema- han categorizado (o más bien reducido) al cine español a una violencia excesiva (1993). Otras, mucho más mesuradas como las de Hopewell, se han referido al residuo animal de conducta que metaforiza las relaciones humanas como una caza (1989: 19) -resabio franquista-, que, en este caso, aparecen literalmente ilustradas con las dilatadas persecuciones de Furio a su presa, "Bambola" (Fig 2).

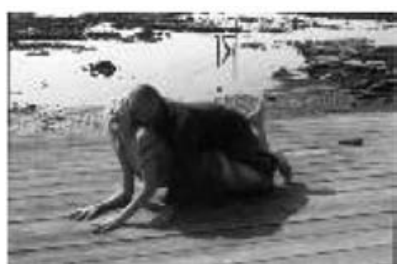

Fig 2: Una de las escenas finales

Título de una popular canción italiana de finales de los años sesenta con la que se abre la película pero también anagrama en castellano de 
la bomba (sexual), Bambola recurre a la combinación de los estamentos mujer ángel-mujer demonio pero no en términos excluyentes que acusan una condición divina -como en Renacer (1982)- o mundana -Lola (1985)-, ni tampoco resultado, siempre excluyente, de una evolución -La camarera del Titanic (1997)-, sino reunidas en una sola figura: es decir, bajo la esfera de una no-disyunción, como una suerte de remanente (aunque exacerbado) de los arquetipos femeninos de Bilbao (1978). Así pues, "Bambola" es ángel en tanto refleja una ingenuidad y un candor tal al punto de resultar inverosímiles, pero tampoco ejerce control sobre su belleza y sensualidad -es cuando pasa a mujerdemonio-, aunado al hecho de que, como sostiene Bataille, toda belleza deseable revela un aspecto animal secreto, gravemente sugestivo (1997: 148): así se evidencia en el plano del baile con Settimio que deja ver sus axilas pilosas (al igual que las de Lulú durante el sexo compartido -el ménage à trois-). Esta marca de sus oquedades remite tanto al prototipo femenino del neorrealismo italiano como a una sexualidad inscrita en esa animalidad de la que ella misma reniega a favor de una relación que atenta no sólo contra su seguridad, sino contra la de seres cercanos como su hermano o su correcto pretendiente Settimio (e incluso la cabra, como se dijo). Su propia contradicción se hace más palpable cuando le dice al exconvicto que prefiere sentirse amada antes que deseada, pero continúa demandando su salvajismo, pues sutilmente le reclama que no le arranque las bragas en el único momento en que no lo hace.

Por eso la victimización de "Bambola" no es pura: forma parte de su complicidad ante una necesidad de dominio, en donde acaso intervenga la ausencia, una vez más en la filmografía de Bigas Luna, de una imagen paterna. El único referente masculino que conoce son aquellos que únicamente se han visto atraídos por su sexo. De ahí que, como Lulú, siga una preferencia de sometimiento hacia una figura dominante que en su caso prefigura una tendencia masoquista: "Siempre me gustaron los hombres fuertes... desde pequeña", murmura antes como excusa que como comentario. Furio es el prototipo del macho llevado al extremo y, tras la repulsión inicial, llega a producir en ella -como ya se plasmara en Lola- una más que clara expresión de amour 


\section{ESPIGA}

fou 4 articulada como una relación sadomasoquista en donde cualquier complementariedad, bajo su prototipo de contrarios, resulta incompatible. Freud fue quien había planteado la correspondencia entre el sadismo (lo activo) con su contraparte, el masoquismo (lo pasivo), la cual posteriormente es disentido por Lacan y Deleuze, quienes no veían concomitancia alguna entre ambas conductas y consideraban que la manifestación del placer de la víctima desactivaba el placer sádico (Gubern, 2002: 189): por eso ninguno de los protagonistas podrían nunca llegar a encontrar correspondencias dentro de sus respectivos paradigmas.

4. Así se plasma la relación en la secuencia de la penetración con la anguila, el "falo eterno" (Costa, 03.11.1996: 55), animal acuático que tiene una similitud con la serpiente, cuyo simbolismo va más allá de lo meramente erótico: la tradición bíblica establece una relación con la mujer que conduce a la tentación y a la muerte (como remisión a la violencia con que su madre destaza las anguilas). Por su pertenencia a las aguas, la anguila es símbolo de regeneración (Eliade, 1988: 162): a la manera de una banda de Moebius, este pez con forma de serpiente enlaza los cuerpos de los amantes, como forma -según Fantoni Minnella- de significar la prolongación infinita del sexo (2000: 92), la consumación de un deseo que sólo se alcanza con la muerte.
La persistencia en su relación con Furio que la desvictimiza sólo se explica por necesidad o costumbre: de ahí el desconsuelo ante su muerte. Fuera de los vínculos de opresión, ella no conoce otro estilo de vida: al lado -o más bien bajo- una figura abusiva -primero su madre Greta Gustafson (nombre verdadero de la Garbo) ${ }^{5}$, que "siempre había sido una mujer difícil... dominante, severa", y luego el feroz Furio-. Desde el acercamiento al rostro de la protagonista en la primera secuencia, hay un dejo de tristeza en su mirada y un tono de voz que prefigura su desgracia. Como Gloria, en ¿Qué he hecho yo para merecer esto? (1984) una vez que ha acabado con la vida de su esposo opresor, "Bambola" no externa sensaciones de alivio porque nunca ha vivido en libertad: una nueva e insospechada etapa de vida se le abre súbitamente. Sin aviso ni preparación se rompen sus cadenas antes de que haya ocurrido lo mismo con sus esquemas mentales; de ahí que, tras la larga persecución final, rompa a

5. Para Riambau, Bigas Luna pretendía una suerte de homenaje a la actriz que la interpretaba, Anita Ekberg -y también, por el componente italiano, a Fellini-, pero lo considera fallido (1996: 12). 
llorar ante el cadáver abatido por su hermano ${ }^{6}$.

De esta forma, Bigas expone lo que podía haber sido una liberación -la muerte de la madre- como una pesadilla, pues es cuando tiene lugar la irrupción de Furio. La pérdida de la condición de objeto en el personaje de "Bambola" -mote italiano que significa muñeca y que como tal supone una vuelta al mundo objectual que Bigas Luna intenta rendir homenaje desde Bilbao- se sugiere, no se escenifica: tendrá lugar tras la secuencia final, cuando se marche en el tren en busca de una nueva vida en otra parte. El simbolismo del viaje forma parte de las etapas del personaje que debe decidir cuál es el siguiente paso que debe tomar en su vida.

6. Como Ely, Flavio reivindica que la construcción de estereotipos erróneamente relacionados con la virilidad -como los cojones de toro- es independiente de sus respectivas condiciones sexuales: ambos son quienes deciden intervenir para poner fin a una situación intolerante. La atribución a la valentía está, en los films de Bigas Luna, vinculada a figuras que la sociedad inscribe como sexualmente disfuncionales.
Son de mary el evangelio de la sentimentalidad (sobre la adaptación)

Es probable que para la génesis de Son de mar (2001) hubiera tenido algún tipo de injerencia el comentario que en su momento hizo Fernando Trueba, uno de los miembros del jurado del premio Alfaguara de 1999, a Andrés Vicente Gómez: "Alguien ha escrito una novela que es una película para Bigas Luna" (Sánchez Costa, 02.06.2001: 7) (Fig 3). También homónima, la novela (1999) de Manuel Vicent no sólo ganó el premio, sino que además se convirtió en un best-seller -cuyas ventas, para la fecha de producción del film, habían superado los 10000 ejemplares-.

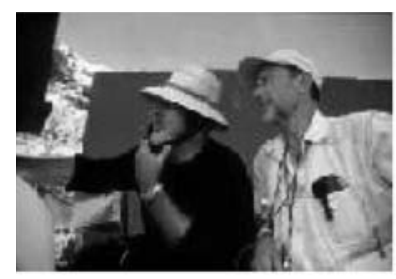

Fig 3: Bigas Luna dirigiendo Son de mar

La elaboración del guión corrió a cargo del prestigioso guionista Rafael Azcona, sin participación, 


\section{ESPIGA}

contrario a lo habitual, de Cuca Canals o del mismo Bigas Luna. Por supuesto que no se sugiere que su ausencia en ese sentido incida desfavorablemente en el resultado, pero tal vez justifique el desaprovechamiento de elementos que figuraban en su filmografía anterior, como que los orígenes de su amor fou no estuvieran expresados en su dimensión total (Casas, 10.06.2001: 2). Aun así, resulta innegable cierta continuidad en la narración, entre la que sobresale la ruptura definitiva del patrón de la mujer cuyo desnivel se extremaba anteriormente bajo su encierro (físico) -Bilbao, Las edades de Lulú (1989), La teta y la luna (1994), Bambola-: lejos de eso, aquí es ella la que, con la anuencia de su primer esposo, lleva a cabo su internamiento en el ático del aislado edificio (lo que refleja una tendencia del director por las reclusiones). Este giro en la posición de lo femenino dentro del cine de Bigas se inserta al mismo tiempo dentro de lo que se venía operando como una progresiva desmitificación de la condición tradicional del macho ibérico ${ }^{7}$.

7. "Estamos asistiendo al declive del macho", ha afirmado el director en una conversación: "El macho ya no se lleva, se va hacia una sociedad más en femenino" (en Muñoz, 2001: 180), como crítica a la sociedad falocrática dominante.
La historia, construida a su vez a partir de un evidente intertexto clásico, gira en torno a la relación entre Martina, la hija del humilde dueño de una pensión, y Ulises Adsuara, un joven profesor de literatura grecolatina que parte a emprender no una guerra que durará diez años sino su propia batalla personal. Si a Horty el mar como sede de sus pasiones y materialización de sus deseos le devuelve a una Marie desconocida, que no tiene nada que ver con la mujer de su relato, a Martina le regresa el hombre que desde adolescente requería o, más bien, el marinero en quien identifica a su esposo desaparecido. Precisamente el simbolismo del mar es un elemento más que contribuye a subrayar esta atmósfera de indefinición: "Todo sale del mar y todo vuelve a él: lugar de los nacimientos, de las transformaciones y de los renacimientos. Aguas en movimiento, la mar simboliza [...] una situación de ambivalencia que es la de la incertidumbre, de la duda, de la indecisión" (Chevalier y Gheebrant, 1998: 689). Ulises -el de Son de mar y el de la Odisea- es purificado y regenerado por las aguas del océano: tras haber sido engullido, su desaparición de la faz de la tierra conduce a que se le identifique con un muerto -en Son de mar hasta se procede a su entierro (convenientemente costea- 
do por Sierra)- pero, tras emerger del océano, retorna al mundo de los vivos. El oscilamiento de ambos mundos se muestra, con inquietante banda sonora, desde la presentación de créditos: el marino, de los muertos, y el terrestre, el de los vivos. Como explica Mircea Eliade, "'vista' desde el nivel neptuniano, la vida humana aparece como una cosa frágil que hay que reabsorber periódicamente, porque el destino de todas las cosas es disolverse a fin de poder reaparecer" (1988: 199). Esta idea se sugería en la piscina con la encarnación de Lola en su hija Ana a partir de la sobreimposición de rostros, y lo mismo pasa con Marie, la camarera impostora, a quien Horty da por muerta, pero regresa, más real, más viva que nunca (y movida por el factor monetario). El agua como nacimiento y vida. Aqua vitae, fons et origo.

Pero Martina no es Penélope, lo que le impide mantenerse en la voluntaria espera, porque su precaria situación económica, aunado a la presión de sus padres, la lleva a contraer matrimonio con su antiguo pretendiente, el millonario Alberto Sierra. Y años después (reducidos en el film), como Lola obsesionada con Mario, acepta a su reaparecido esposo (o a alguien que le resulta idéntico) -lo cual, sin embargo, no deja de ser también una forma de espera -8 . Precisamente aquí se está ante el quid del asunto: la adaptación rechaza el soporte esencial sobre el que se articula la historia, esto es, el conflicto que suscita la identidad del recién llegado. Esta observación ha de matizarse recordando una vez más lo reproducido por Sánchez Noriega, a saber, que la fidelidad al texto original no representa ninguna garantía. El problema es que en este caso se trata de uno de los pilares sobre los que se asienta el conflicto.

La novela de Vicent -por lo demás, idónea para su traslación al lenguaje fílmico- comenzaba con el singular hallazgo de dos cuerpos vestidos de novios en sitios diferentes -aunque más o menos cercanos- de la costa mediterránea, lo cual daba paso al misterio colectivo suscitado a raíz de la indagación de la identidad del varón.

8. Esta circunstancia supone una reproducción de las funciones genéricas tradicionales que ya se habían planteado en Bilbao: Ulises, nómada, el viaje (lo activo) y Martina-Penélope, lo sedentario, la espera (lo pasivo). "Históricamente, el discurso de la ausencia lo pronuncia la Mujer: la Mujer es sedentaria, el Hombre es cazador, viajero; la Mujer es fiel (espera), el Hombre es rondador (navega, rúa). Es la Mujer quien da forma a la ausencia, quien elabora la ficción, puesto que tiene el tiempo para ello..." (Barthes, 1997: 45-46). 


\section{ESPIGA}

Después de una hora de discusión se llegó al acuerdo que se necesitaba más superficie de piel para reconocer a aquel ser que había vomitado el Mediterráneo. En estos casos siempre existe una peca secreta que soluciona la identidad de las personas, ese código del tacto que sólo conocen los amantes en la oscuridad, pero allí no había nadie, ni siquiera su amigo íntimo Xavier Leal, que aportara una prueba inequívoca sobre la identidad del náufrago [énfasis agregado] (Vicent, 1999: 17).

El enigma de la personalidad de Ulises $^{9}$ era sostenido casi hasta el final de la novela, a lo largo de la cual el escritor valenciano ofrecía información confusa ex profeso. Así, a pesar de que el personaje que regresa reconoce a su hijo y recuerda hasta el más mínimo detalle de su antigua relación es el mismo, existen indicios que hacen sospechar de la suplantación de identidad -a la manera de la cinta francesa El retorno de Martin Guerre (Le Retour de Martin Guerre, 1981), de Daniel Vigne-, a saber, el nombre registrado en su pasaporte

9. Cuyo prototipo como aventurero homérico exige, por tradición literaria, prolongar la irresolución, tal y como se opera en el héroe griego -donde su perro, que lo esperaba para morir a sus pies, es el único que ejerce el reconocimiento (anagnórisis)-.
(Andreas Mistakis), la diferente tonalidad de sus ojos, una corpulencia física más fornida, la ausencia de la casi secreta peca rubia, pero sobre todo, una conducta marcadamente más pasional que la del absorto y retraído profesor: "Sus brazos parecían más fuertes o tal vez sabían abrazar mejor; su voz era más segura; su pecho estaba más curtido" (Vicent, 1999: 238). Aunque calla, la propia Martina nunca muestra mayor interés por esclarecer la identidad del que se le presenta como su esposo, y espera al último momento para indagarlo: “¿Quién eres? Ahora que vamos a morir dime quién eres", sin obtener por respuesta más que el eco de la misma pregunta -“¿Quién eres tú?” (Vicent, 1999: 324)-, lo que permitía entrever el complejo fenómeno de las identidades humanas. Finalmente, tras haber sostenido la ambigüedad de su identidad a partir de su reaparición, la polémica general sobre el cadáver se sella cuando el juzgado obtiene la respuesta definitiva en que solicitaba el contraste de las huellas dactilares del ahogado con las del auténtico profesor:

El cura inició la liturgia de difuntos dando por supuesto que el muerto era Ulises Adsuara, ya que ésa era la opinión mayoritaria, pero 
en ese momento ya se sabía en el juzgado que las huellas del náufrago correspondían exactamente a las del pasaporte de Andreas Mistakis, natural de Corfú [énfasis agregado] (Vicent, 1999: 331).

La ambigüedad de la identidad, al no trasladarse (desde la modificación o el replanteamiento) al guión, marca cierta ruptura de Bigas no sólo con el eje de la novela, sino con su trayectoria fílmica. Porque de una u otra forma, en las cuatro obras literarias anteriormente adaptadas venía implícita la controversia por la identidad de sus personajes, empezando por Tatuaje (1977), que giraba en torno a las averiguaciones de Pepe Carvalho a fin de descubrir quién era el cadáver encontrado en la playa y las razones de su muerte, cuestión abordada de manera más tangencial en la novela de Almudena Grandes, donde se destacaban -aunque de manera sutil- las identidades (edades) de Lulú en relación con su sexualidad. Y aunque la crítica haya cuestionado el guión de Volavérunt (1999), no así el de La camarera del Titanic (que recibió distinciones al mejor guión adaptado por distintos festivales y agrupaciones), ambos films -uno más que otro- mostraban, a diferencia de sus novelas de base, la particularidad de generar situaciones de incertidum- bre a partir de sus personajes así como de enriquecer la adaptación con la incorporación de otros elementos (como la ambigüedad), todo lo cual venía a desmentir ese lugar común de que la novela es invariablemente mejor que la película.

En cambio, aquí la confusión identitaria cede toda su propuesta de fondo a una historia romántica desde una dosis de erotismo y con personajes un tanto simplificados. Las dos últimas escenas -las referidas a las muertes de los protagonistas- sustituyen la polémica colectiva de la playa en torno a la personalidad del inanimado Ulises -o el supuesto Ulises- por un idílico final de tendencia cosmomórfica, donde, desde un plano entero de ambos cuerpos desnudos, las camillas de la morgue se transforman en las aguas del mar que una vez los separó y ahora los reúne. La ausencia de problematización de identidad, sustituida por una idealización del amor -que también se repetía en Las edades de Lulú-, constituye una de las diferencias constantes y determinantes en las adaptaciones literarias al cine. Es indiscutible que de lo que se trata no es de cuestionar la sustitución de unas acciones por otras, sino su pertinencia, esto es, las razones a las que responden. 
De ahí que el cierre ${ }^{10}$ aparece indefectiblemente ligado con lo que Baudrillard llama el evangelio de la sentimentalidad, propio de una nueva época a la que el mundo está asistiendo que el cine tiende a suscribir ${ }^{11}$.

10. Sánchez Noriega apunta que "[e]n no pocas adaptaciones, los finales de los textos literarios se dulcifican para mitigar el desasosiego que provoca el fracaso del héroe, hacer converger los itinerarios sentimentales hacia el ideal de la plenitud amorosa [...]; en definitiva, a desterrar del relato todo carácter trágico y toda visión cruda de la realidad en beneficio de un talante conciliador que potencia los aspectos optimistas de la condición humana. La cultura de masas en la que se ubica el cine mayoritario propone transformaciones radicales respecto a la novela o al teatro [...], puesto que la pretensión comercial y las pautas de consumo que establece niegan la muerte y las dimensiones trágica y agónica de la existencia" (2000: 125).

11. Que identifica como neorromántica: "Lo que está en juego actualmente es una una demanda de amor, de afecto, de pasión, en una época en que su necesidad se hace sentir cruelmente. Es toda la generación que ha pasado por la liberación del deseo y del placer, toda esa generación fatigada de sexo la que reinventa el amor, como suplemento afectivo o pasional [...] Después del pathos sexual, aparece el neopatetismo de la relación amorosa. Después de lo libidinal y de lo pulsional, el neorromanticismo de la pasión" (1997: 107).

\author{
BAMBOLA \\ 1996 \\ Coproducción italiana (70\%) \\ y española (30\%) \\ Estreno en España: \\ 25.10.1996
}

Productoras:

Rodeo Drive (Italia), Starline TV

Productions, con la colaboración de Televisión Española (TVE) y

Canal Plus

Productor ejecutivo:

Juan Alexander

Dirección:

Bigas Luna

Argumento:

Cesare Frugoni

Guión:

Bigas Luna, Cesare Frugoni

Fotografía:

Fabio Conversi (color)

Ambientación/Decoración:

Gualtiero Caprara

Vestuario:

Mercedes Gutiérrez

Montaje:

Gianfranco Amicucci 
Sonido:

Roberto Petrozzi

Música:

Lucio Dalla

Principales intérpretes:

Valeria Marini (Mina, "Bambola"), Stefano Dionisi (Flavio), Jorge

Perugorría (Furio), Manuel

Bandera (Settimio), Antonino

Iuorio (Ugo), Anita Ekberg (madre), Arsenio Luna (Arsenio)

Duración:

$90 \mathrm{~min}$

Sinopsis:

Mina es una joven de gran belleza y sensualidad que responde al mote de "Bambola". Al morir la madre, ella y su hermano Flavio instalan una pizzería con el apoyo financiero de Ugo, un amigo de aquel que se ve atraído por la joven. Un día "Bambola" conoce en el balneario a Settimio y Ugo, movido por los celos, provoca una riña. Como resultado, muere por accidente y Settimio es encarcelado, acusado de asesinato. En las visitas a la cárcel, el preso más violento preso, Furio, enloquece de pasión por ella y se ensaña con Settimio. Flavio, enamorado a su vez de Settimio, le pide a su hermana que interceda ante Furio, y cuando ésta se presenta ante el agresivo preso, la obliga a mantener relaciones sexuales, aunque en el fondo lo consiente, pues vuelve días después. Una vez libre, Furio se instala a vivir en la casa de los hermanos, pero los celos y la violencia van en aumento hasta niveles de convivencia insoportable que terminan que Flavio termine ejecutándolo de un disparo. Finalmente, Settimio sale de prisión, se instala a vivir con Flavio y "Bambola", embarazada, se marcha a buscar una nueva vida.

\section{SON DE MAR}

2001

Estreno en España:

08.06.2001

Producción:

Lola Films con la participación de Antena 3 TV y Vía Digital

Producción ejecutiva:

Andrés Vicente Gómez

Dirección:

Bigas Luna

Argumento:

Manuel Vicent, basado

en su novela homónima 


\section{ESPIGA}

Guión:

Rafael Azcona

Fotografía:

José Luis Alcaine (color)

Ambientación/Decoración:

Pierre Thevenet

Vestuario:

Macarena Soto

Montaje:

Ernest Blasi

Música:

Piano Magic

Sonido:

Albert Manera

Principales intérpretes:

Jordi Mollà (Ulises), Leonor

Watling (Martina), Eduard

Fernández (Alberto Sierra), Sergio

Caballero (Xavier), Neus Agulló

(Roseta), Pep Cortés (Basilio),

Juan Muñoz (director del

Instituto), Ricky Colomer (Abel)
Sinopsis:

Ulises es un joven profesor de literatura clásica que llega a sustituir a un profesor en un instituto de la costa mediterránea. Se aloja en una pensión donde conoce a Martina, la hija de los dueños. Tras quedar embarazada, se casan, construyen un hogar y Ulises adquiere un barco. Un día no regresa y el barco aparece luego destrozado por las olas. Al no aparecer el cuerpo, es dado por muerto y Martina se casa luego con su antiguo pretendiente, Alberto Sierra, que cría al hijo de ella como propio. Años después, una llamada de Ulises sobresalta a Martina. Se produce el reencuentro sexual, a partir del cual Martina decide alojar a su antiguo marido en el ático de unos edificios deshabitados de su esposo. Pronto Sierra lo descubre y Martina le comunica su decisión de abandonar el hogar. Embarca con Ulises, pero en alta mar el barco se inunda y ambos mueren.

Duración:

$100 \mathrm{~min}$ 
FUENTES CONSULTADAS

\section{Libros}

AUMONT, Jacques / Marie, Michel (1993): Análisis del film. Barcelona: Paidós, $2^{\mathrm{a}} \mathrm{Ed}$.

AUMONT, Jacques et alt. (1996): Estética del cine. Barcelona: Paidós, $2^{\text {a }}$ Ed.

BARTHES, Roland (1997): Fragmentos de un discurso amoroso. Madrid: Siglo XXI, $13^{\circ} \mathrm{Ed}$.

BASSA, Joan / FREIXAS, Ramon (1996): Expediente "S". Softcore, Sexploitation, Cine "S". Barcelona: Futura.

BATAILLE, Georges (1997): El erotismo. Barcelona: Tusquets.

BAUDRILLARD, Jean (1997): Las estrategias fatales. Barcelona: Anagrama.

CARMONA, Ramón (1993): Cómo se comenta un texto fílmico. Madrid: Cátedra, $3^{\mathrm{a}} \mathrm{Ed}$.

CASETTI, Francesco / DI CHIO, Federico (1998): Cómo analizar un film. Barcelona: Paidós.

CHEVALIER, Jean / GHEEBRANT, Alain (1998): Diccionario de los símbolos. Barcelona: Herder, $2^{a}$ Ed.

ELIADE, Mircea (1988): Tratado de historia de las religiones. México: Era, $6^{\text {a }} \mathrm{Ed}$.

ESPELT, Ramon (intr.) (1989): Mirada al món de Bigas Luna. Barcelona: Laertes.

FALCÓN MARTÍNEZ, Constantino / FERNÁNDEZ-GALIANO, Emilio / LÓPEZ MELERO, Raquel (1986): Diccionario de la mitología clásica (I y II). Madrid: Alianza.

FANTONI MINNELLA, Maurizio (2000): Bigas Luna. Roma: Gremese Editore.

FREIXAS, Ramon / BASSA, Joan (2000): El sexo en el cine y el cine de sexo. Barcelona: Paidós.
FREUD, Sigmund (1975): Tres ensayos sobre teoría sexual. Madrid: Alianza, $3^{\mathrm{a}} \mathrm{Ed}$.

GIRARD, René (1983): La violencia y lo sagrado. Barcelona: Anagrama.

GRANDES, Almudena (2000): Las edades de Lulú. Barcelona: Grijalbo Mondadori.

GUBERN, Román et alt. (1997): Historia del cine español. Madrid: Cátedra, $2^{\mathrm{a}} \mathrm{Ed}$.

(2000): El eros electrónico. Madrid: Taurus.

(2002): Máscaras de la ficción. Barcelona: Anagrama.

(2005). La imagen pornográfica y otras perversiones ópticas. Barcelona: Anagrama.

HOMERO (2000): Odisea. Madrid: Gredos.

KINDER, Marsha (1993): Blood Cinema: The Reconstruction of National Identity in Spain. Berkeley \& Los Angeles: University of California Press, 1993.

PÉREZ PERUCHA, Julio (ed.) (1997): Antología crítica del cine español 19061995. Madrid: Cátedra.

PISANO, Isabel (2001): Bigas Luna: sombras de Bigas, luces de Luna. Madrid: Sociedad General de Autores y Editores.

RIAMBAU, Esteve / TORREIRO, Casimiro (1999a): Historias, palabras, imágenes. Entrevistas con guionistas del cine español contemporáneo. Madrid: XXIX Festival de Cine de Alcalá de Henares.

(1999b): La Escuela de Barcelona: el cine de la "gauche divine". Barcelona: Anagrama.

ROMAGUERA I RAMIÓ, Joaquim (dir.) (2005): Diccionari del cinema a Catalunya. Barcelona: Enciclopèdia Catalana.

SÁINZ, Salvador (1994): El cine erótico. España: Royal Books. 


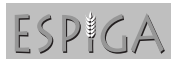

SCREEN (1992): The Sexual Subject. New York: Routledge.

SEGUIN, Jean-Claude: "La métamorphose des corps". En VV. AA. (2001), Le cinéma de Bigas Luna. Toulouse: Presses Universitaires du Mirail.

SÁNCHEZ, Alberto (ed.) (1999): Bigas Luna. La fiesta de las imágenes. Huesca, España: Gráficas Alós.

SÁNCHEZ NORIEGA, José Luis (2000): De la literatura al cine. Barcelona: Paidós.

VANOYE, Francis (1996): Guiones modelo y modelos de guión. Barcelona: Paidós.

VICENT, Manuel (1999): Son de mar. Madrid: Alfaguara.

\section{Prensa}

CASAS, Quim: "Son de mar, passió devoradora y minimalisme mediterrani", El Periódico, 10.06.2001: 2.

COSTA, Jordi: “Això és una dona!", Avui, 03.11.1996: 55.

MARTÍ FONT, Josep Maria: "Bigas Luna: 'En Bambola busqué el exceso'", El País, 22.10.1996: 37.

MUÑOZ, José Luis: "El arte del erotismo", DT, julio/agosto 2001: 180-181.

: “Olas de pasión", B y N Dominical, I (31), 03.06.2001: 66-73.

RIAMBAU, Esteve: "Bambola", Fotogramas, XVIX, (1836), octubre 1996: 12.

SÁNCHEZ COSTA, Joan Josep: "Bigas Luna retrata un triángulo amoroso", El Periódico, 02.06.2001: 7.

VALL, Pere: "Bigas Luna, descubridor de talentos", Fotogramas, LIV, (1892), junio 2001: 120-126. 